\title{
PREVALENCE OF LESIONS ASSOCIATED WITH TRAUMATIC RECURRENT SHOULDER DISLOCATION
}

Oreste Lemos Carrazzone', Marcel Jun Sugawara Tamaoki', Luiz Felipe Morlin Ambra², Nicola Archetti Neto ${ }^{3}$, Marcelo Hide Matsumoto ${ }^{4}$, João Carlos Belloti ${ }^{5}$

\section{ABSTRACT}

Objective: To evaluate the prevalence of lesions associated with traumatic anterior shoulder instability and the relationships between the prevalence of these lesions and the number of episodes and time since symptoms started. Method: Fifty-seven patients aged 18 to 40 years, with traumatic anterior shoulder instability, more than one episode of shoulder dislocation and at least six months since the first dislocation, who required surgery to treat the instability, were selected. Arthroscopic inspection was performed on all the patients to assess any associated lesions. Results: The prevalence of lesions was assessed, and Bankart lesions were the most prevalent, followed by Hill-Sachs lesions, while rotator cuff injuries were the least prevalent. There was no correlation from comparison between the number of episodes of dislocation and the prevalence of associated lesions. On the other hand, in relation to the time since symptoms started, the patients who had had symptoms for longer times had fewer Hill-Sachs lesions. Conclusion: It was not possible to affirm that, in patients with chronic shoulder instability, the numbers of associated lesions increased with the time since symptoms started, or with the number of episodes of dislocation.

Keywords - Shoulder Dislocations/complications; Joint Instability/complications; Arthroscopy

\section{INTRODUCTION}

Dislocation of the shoulder joint occurs in 1 to $2 \%$ of the population ${ }^{(1)}$. Its incidence is $1.7 \%$ among adults and it is three times more common among men $^{(2)}$. Ninety percent of shoulder dislocations are anterior $^{(3)}$, and traumatic injuries account for $95 \%$ of them ${ }^{(4-7)}$. In athletic patients under the age of 20 years, the recurrence rates are greater than 90\%. Among patients aged 20 to 25 years, the rates are between 50 and $75 \%{ }^{(4-7)}$.

It is not fully clear in the literature, among patients who present multiple episodes of dislocation, whether the time of the dislocation or the numbers of dislocations have any relationship with associated intra-articular lesions, such as Bankart lesion, biceps lesion or impaction fractures of the humeral head (Hill-Sachs lesion), among others.

We drew up this study based on the hypothesis that greater numbers of episodes of dislocation and chronic occurrence of symptoms of instability would lead to greater prevalence of associated lesions.

The aims of this study were to assess the prevalence of lesions associated with traumatic anterior stability of the shoulder and, furthermore, to assess whether the number of episodes and the time of onset of symptoms had any association with the prevalence of such lesions.

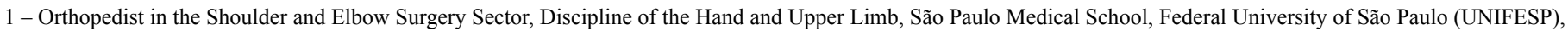
São Paulo, Brazil.

2 - Resident Physician in the Department of Orthopedics and Traumatology, São Paulo Medical School, Federal University of São Paulo (UNIFESP), São Paulo, Brazil.

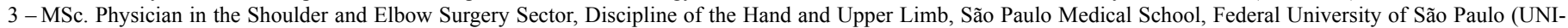
FESP), São Paulo, Brazil.

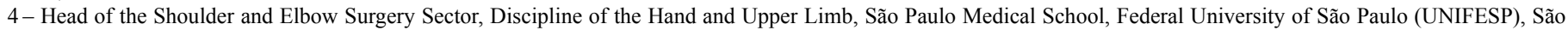
Paulo, Brazil.

5 - PhD. Physician in the Department of Orthopedics and Traumatology, São Paulo Medical School, Federal University of São Paulo (UNIFESP), São Paulo, Brazil.
}

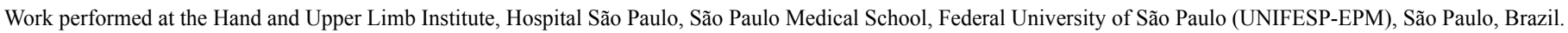
Correspondence: Luiz Felipe Morlin Ambra - Rua Caraíbas, 666, apto. 101, Perdizes - 05020-030 - São Paulo, SP. E-mail: oreste68@hotmail.com

Work received for publication: May 20, 2010; accepted for publication: December 23, 2010 


\section{MATERIAL AND METHOD}

Patients with traumatic anterior instability of the shoulder who were attended at the Shoulder and Elbow Service of the Department of Orthopedics and Traumatology, Federal University of São Paulo, between 2005 and 2007, were retrospectively assessed.

The inclusion criteria were that all patients of both sexes between 18 and 40 years of age were selected if they had had more than one episode of shoulder dislocation and more than six months had passed since the first dislocation, and if the cases were documented with radiographs and the clinical history. All the patients included required surgery to treat traumatic anterior instability. The patients' ages were defined as up to 40 years, since after this age, degenerative lesions are more commonly present, which could be a confounding factor for data analysis.

Patients who refused to sign the consent statement, those who had previously undergone shoulder surgery and those who had diagnoses of collagen disease were excluded.

At the preoperative assessment, the patients underwent a rigorous physical examination, in which the diagnosis of anterior instability was confirmed. As auxiliary diagnostic methods, radiographs were produced in the true frontal, lateral scapular and axillary views.

The patients underwent interscalene brachial plexus block through the use of bupivacaine and lidocaine hydrochloride, along with general inhaled anesthesia. The patients were kept in the deckchair position during the surgical procedure. For the arthroscopic inspection, a posterior portal was used for initially introducing the optical device, and this was also used for infusing physiological serum. The anterior portal was established with the long head of the biceps as the reference point, and this was used to introduce a probe through a plastic cannula was introduced in order to palpate the structures, which were assessed in the following sequence:

The posterior portal used to view the long head of the biceps; anterosuperior labral capsular complex; joint surfaces of the humerus and glenoid; anterior, posterior and inferior labrums; supraspinal, infraspinal and subscapular tendons; axillary recess; and posterior region of the humeral head.

Rev Bras Ortop. 2011;46(3):281-87
The anterior portal was used to view the format of the glenoid; the anterior and posterior labrums; the posterior margin of the glenoid; and the posterior capsule.

In this manner, we identified the main secondary lesions associated with recurrent dislocation of the shoulder, which are the following: Bankart lesions, SLAP lesions, chondral lesions in the glenoid and humeral head, bone lesions in the glenoid, Hill-Sachs lesions, rotator cuff lesions and lesions of the long head of the biceps.

The descriptions of these findings was noted down in the patients' medical files, along with their personal data such as age, sex, profession, dominant side, trauma mechanism, time since the first dislocation and number of episodes of dislocation (Annex 1).

After the arthroscopic inspection, the patients underwent correction of the instability by means of the surgical method that had previously been indicated.

These data were subjected to statistical analysis to correlate between the length of time with symptoms, the number of dislocations and the associated lesions.

This project was approved by the Research Ethics Committee of UNIFESP, under the number 0901/03.

\section{RESULTS}

Seventy-three patients were initially selected. Of these, six were excluded because they presented an initial acute episode (with less than six months of evolution); three refused to sign the consent statement for their participation in the study; and seven were outside of the proposed age range. Thus, the final sample was 57 patients.

The patients' mean age was $27.3 \pm 6.19$ years, with a range from 18 to 39 years. Fifty-two patients $(91.2 \%)$ presented right-side dominance and five $(8.8 \%)$ had left-side dominance. For 33 patients $(57.9 \%)$, the side affected was the right side, while for $24(42.1 \%)$, it was the left side. Forty-six patients $(80.7 \%)$ did not do sports activities or work activities involving the upper limbs.

Among the associated lesions, Bankart lesions had the highest prevalence and were found in all the patients. The second most frequent type was Hill-Sachs lesions, in $71.9 \%$ of the patients. Rotator cuff lesions were the least prevalent type, seen in only one patient (1.8\%) (Table 1). 
Annex 1 - Evaluation Questionnaire

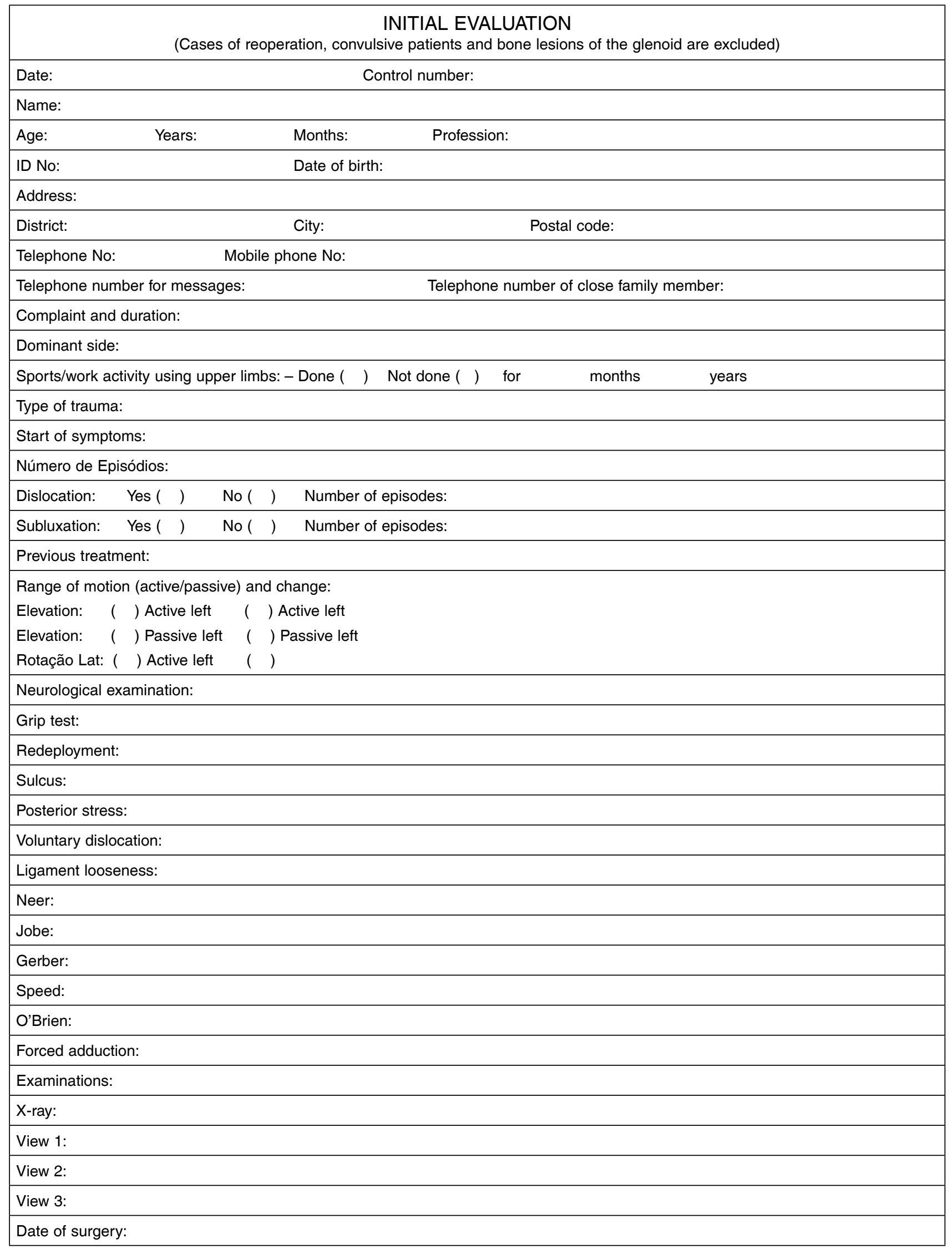


Annex 1 - Evaluation Questionnaire

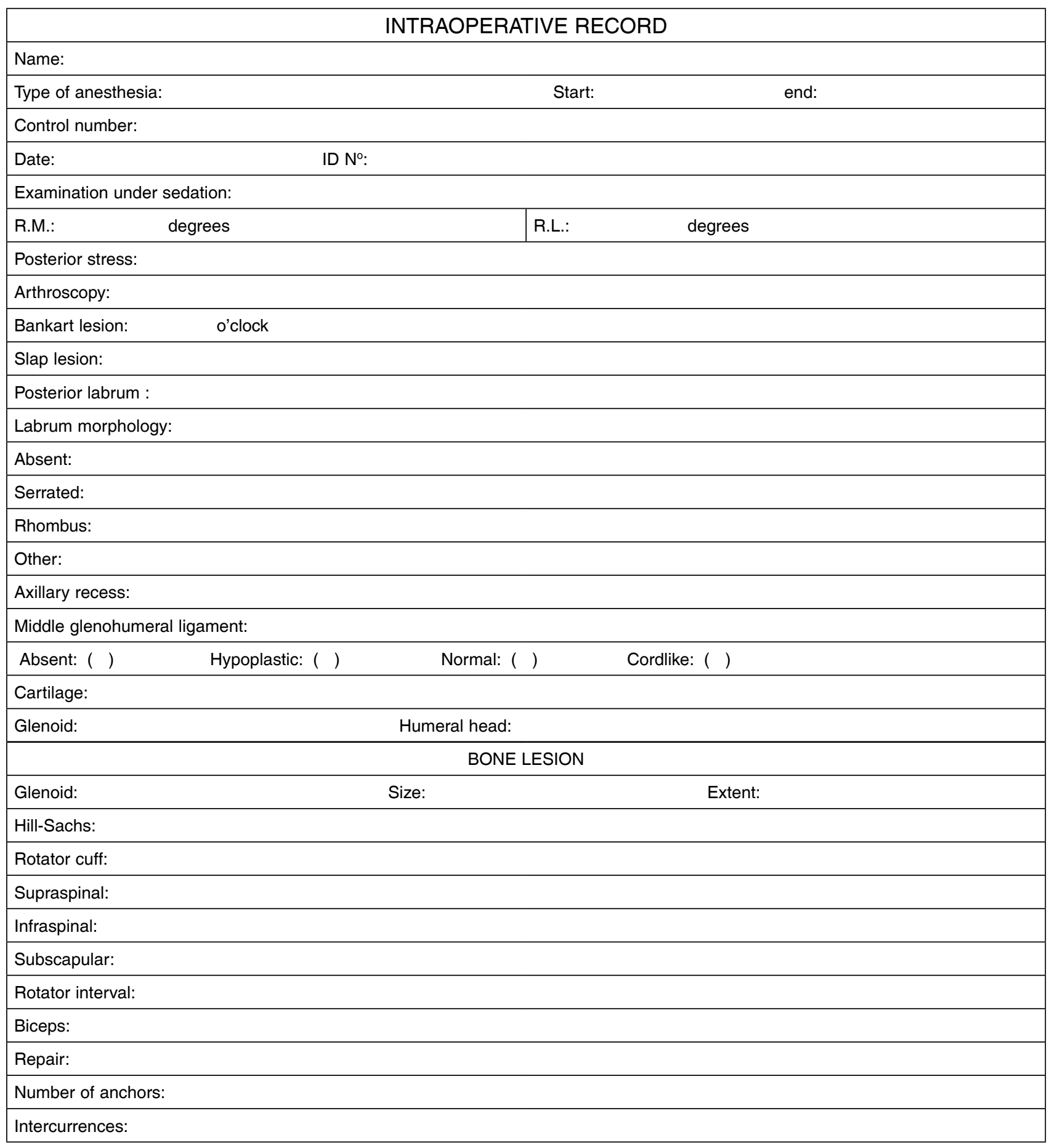


To compare the arthroscopic findings, the individuals were firstly divided into two groups according to the number of episodes of dislocation. Group I was defined as two to nine episodes and group II as ten or more episodes (Table 2).

The two groups had mean ages (group I, 27 years and group II, 27.4 years) and lengths of time with symptoms (group I, 50 months and group II, 52.3 months) that were very close. In Table 2 , it can be seen that there were no statistically significant differences between groups I and II. There was no correlation between the number of episodes of dislocation and the prevalence of associated lesions.

Following this, it was decided to divide the individuals into two groups using the length of time with symptoms as the criterion. In group A, the individuals had had symptoms for up to two years, and in group $\mathrm{B}$, for more than two years (Table 3 ). The mean ages of the two groups were very similar. We found a sta-

Table 1 - Prevalence of associated lesions.

\begin{tabular}{c|c|c}
\hline Lesion & $\mathbf{n}$ & $\%$ \\
\hline Bankart lesion & 57 & 100 \\
\hline Hill-Sachs lesion & 41 & 71.9 \\
\hline SLAP lesion & 22 & 38.6 \\
\hline Bone lesion of the glenoid & 18 & 31.6 \\
\hline Chondral lesion & 16 & 28 \\
\hline Lesion of the long head of the biceps & 8 & 14 \\
\hline Rotator cuff lesion & 1 & 1.8 \\
\hline
\end{tabular}

Table 2 - Associated lesions according to number of episodes of dislocation.

\begin{tabular}{|c|c|c|c|c|}
\hline Parameter & $\begin{array}{c}\text { GROUP I } \\
2 \text { to } 9 \\
\text { dislocations } \\
(n=24)\end{array}$ & $\begin{array}{c}\text { GROUP II } \\
10 \text { or more } \\
\text { dislocations } \\
(n=33)\end{array}$ & $\begin{array}{c}P \\
\text { value }\end{array}$ & $\begin{array}{c}\text { Total } \\
(\mathrm{n}=57)\end{array}$ \\
\hline $\begin{array}{l}\text { Length of time with } \\
\text { symptoms (months) }\end{array}$ & $\begin{array}{c}50.0( \pm \\
51.1)\end{array}$ & $52.3( \pm 46.0)$ & $0.48^{(\mathrm{a})}$ & $\begin{array}{c}51.3( \pm \\
47.8)\end{array}$ \\
\hline Bankart lesion $(n)$ & $24(100 \%)$ & $33(100 \%)$ & - & $57(100 \%)$ \\
\hline SLAP lesion (n) & $9(37.5 \%)$ & $13(39.4 \%)$ & $0.88^{(\mathrm{b})}$ & $22(38.6 \%)$ \\
\hline Chondral lesion (n) & $6(25 \%)$ & $10(30.3 \%)$ & $0.44^{(\mathrm{b})}$ & $16(28 \%)$ \\
\hline $\begin{array}{l}\text { Bone lesion in } \\
\text { glenoid }(n)\end{array}$ & $6(25 \%)$ & $12(36.4 \%)$ & $0.40^{(\mathrm{b})}$ & $18(31.6 \%)$ \\
\hline $\begin{array}{l}\text { Hill-Sachs lesion } \\
\text { (n) }\end{array}$ & $19(79.2 \%)$ & $22(66.7 \%)$ & $0.37^{(\mathrm{b})}$ & $41(71.9 \%)$ \\
\hline $\begin{array}{l}\text { Rotator cuff lesion } \\
\text { (n) }\end{array}$ & 0 & $1(3.8 \%)$ & - & $1(1.8 \%)$ \\
\hline $\begin{array}{l}\text { Lesion of the long } \\
\text { head of the biceps } \\
\text { (n) }\end{array}$ & $4(16.7 \%)$ & $4(12.1 \%)$ & $0.62^{(\mathrm{b})}$ & $8(14 \%)$ \\
\hline
\end{tabular}

Table 3 - Arthroscopic findings according to length of time with symptoms.

\begin{tabular}{|c|c|c|c|c|}
\hline $\begin{array}{c}\text { Parameter } \\
\text { (length of time } \\
\text { with symptoms) }\end{array}$ & $\begin{array}{l}\text { Group A } \\
\text { Up to } 2 \\
\text { years } \\
(n=25)\end{array}$ & $\begin{array}{c}\text { Group B } \\
\text { More than } 2 \\
\text { years } \\
(\mathbf{n}=\mathbf{3 2})\end{array}$ & $\begin{array}{c}P \\
\text { value }\end{array}$ & Total \\
\hline Bankart lesion (n) & 25 (100\%) & $32(100 \%)$ & - & $57(100 \%)$ \\
\hline SLAP lesion (n) & $10(45.5 \%)$ & $15(42.9 \%)$ & $0.84^{(\mathrm{b})}$ & 25 (43.9\%) \\
\hline Chondral lesion (n) & $6(37.5 \%)$ & $5(35.7 \%)$ & $0.54^{(\mathrm{b})}$ & $16(28 \%)$ \\
\hline $\begin{array}{l}\text { Bone lesion in } \\
\text { glenoid }(n)\end{array}$ & $7(28 \%)$ & $11(34.4 \%)$ & $0.60^{(b)}$ & $18(31.6 \%)$ \\
\hline $\begin{array}{c}\text { Hill-Sachs lesion } \\
(\mathrm{n})\end{array}$ & 22 (88\%) & $19(59.4 \%)$ & $0.01^{*(b)}$ & $41(71.9 \%)$ \\
\hline $\begin{array}{l}\text { Rotator cuff lesion } \\
\text { (n) }\end{array}$ & 0 & $1(3.8 \%)$ & - & $1(1.8 \%)$ \\
\hline $\begin{array}{l}\text { Lesion of the long } \\
\text { head of the biceps } \\
\text { (n) }\end{array}$ & $2(8 \%)$ & $6(18.8 \%)$ & $0.24^{(\mathrm{b})}$ & $8(14 \%)$ \\
\hline
\end{tabular}

$\mathrm{a}=$ Kruskal-Wallis test; $\mathrm{b}=$ chi-square test; ${ }^{*} \mathrm{p} \leq 0.05$

tistical difference when comparing the groups in relation to Hill-Sachs lesions: the patients with symptoms for longer times had fewer Hill-Sachs lesions. For the other parameters, we did not find any statistically significant differences between the groups.

Studies correlating the duration of instability and number of dislocations with degenerative and associated lesions in the shoulder are scarce in the literatu$\mathrm{re}^{(5,6)}$, and there is still some doubt as to whether any positive correlation exists between these variables.

Yiannakopoulos et $\mathrm{al}^{(8)}$ evaluated a series of 127 patients, among whom 23 underwent arthroscopy two to ten days after the first episode of dislocation, i.e. acute cases, while the remainder were considered to be chronic cases. They concluded that the prevalence of associated lesions was greater among the chronic patients.

Taking into consideration only the patients with chronic instability, the prevalence in our study was similar to what was found by Yiannakopoulos, who found Bankart lesions in $97.11 \%$ of their patients, Hill-Sachs lesions in $93.26 \%$, bone lesions of the glenoid in $10.57 \%$, SLAP lesions in $20.19 \%$ and rotator cuff lesions in $11.53 \%$. The difference in our study was that we only evaluated chronic patients.

The prevalence of fractures or erosion of the anteroinferior margin of the glenoid in shoulders with recurrent anterior dislocation has been reported to 
range from $8 \%$ (18 out of 226 ) to $73 \%$ (116 out of $158)^{(9-13)}$. In the present survey, the prevalence found was $31.6 \%$. The correlation between these lesions and the length of time with symptoms or with the number of episodes was not statistically significant, although the percentage increased both with the time and the number of episodes.

We found Hill-Sachs lesions (fractures due to pressure on the humeral head) in $71.9 \%$ of the patients, which is concordant with the literature ${ }^{(14-16)}$. However, there was no correlation with the length of time with symptoms or the number of episodes of dislocation.

Bankart $^{(17,18)}$ maintained that the lesion responsible for recurrent anterior luxations was detachment of the capsule and labrum from the margin of the glenoid. The incidence that we found was in agreement with previous studies, in which this defect was found in $97 \%$ of the patients with traumatic recurrence of anterior dislocation ${ }^{(19)}$. In our survey, all the patients had lesions of the anteroinferior labral capsular, without any difference between the groups. One failure in our study was that the size of the labral lesion and the tissue quality were not evaluated, although these may have had a relationship with the chronic nature and number of episodes of dislocations.

Andrews et $\mathrm{al}^{(20)}$ were the first to describe anterosuperior labral lesions in athletes participating in throwing events. Snyder et al ${ }^{(21)}$ contributed with the first comprehensive description and classification of lesions of the superior labrum in 1990 and introduced the term "superior labrum anterior to posterior" (SLAP), referring to lesions of the labrum in its upper portion. Snyder et al emphasized that these lesions were relatively rare, with an incidence of $6 \%$ in their population-based study (present in 140 of their 2375 cases). Other researchers have reported incidences of between $6 \%$ and $12 \%{ }^{(22)}$. The incidence of SLAP lesions may increase in situations of shoulder dislocation and may reach more than $20 \%$, but without any significant difference between acute and chronic cases ${ }^{(8)}$.

In our survey, comparing patients with two or more episodes of dislocation and a minimum of six months of symptoms of instability, despite an increase, no significant difference between the groups was observed regarding the prevalence of SLAP lesions. The total prevalence was $38.6 \%$ (22 patients).

The frequency of rotator cuff lesions following traumatic dislocation increases with increasing age $^{(23,24)}$, although the incidence of preexisting rotator cuff lesions is unknown. Despite demonstrations in other series ${ }^{(8,12)}$ of high associations of cuff lesions with anterior instability of the shoulder and evidence that repeated episodes of shoulder dislocation are a potential risk factor for increased frequency of rotator cuff lesions, the present survey showed that rotator cuff lesions only affected $1.8 \%$ of the patients (i.e. a single case). This finding is not compatible with the literature and was probably due to the low age group of the patients evaluated (under 40 years of age).

The initial hypothesis of this study was that the longer for which symptoms had been present and the greater the number of episodes of dislocation, the more degenerative and associated lesions the patient would have. This suspicion was based on studies on other joints, like the knee, in which delays in ligament reconstruction lead to early degeneration of the joint.

However, our results did not demonstrate this relationship. Hovelius et $\mathrm{al}^{(7)}$ demonstrated that over a 10-year follow-up, among patients with an episode of anterior dislocation but without recurrence of the dislocation, the incidence of moderate to severe shoulder arthrosis was 6\%. An additional 10\% had mild arthrosis.

The possible cause is that the shoulder joint presents different biomechanics of movements and does not tolerate the load imposed on the lower limbs. Moreover, the mean age among our patients was deliberately low, precisely to avoid the bias of the presence of degenerative lesions, which are inherent to physiological aging of the joint. It is also possible that future studies with longer duration of symptoms or greater numbers of dislocations will show this correlation.

\section{CONCLUSION}

Bankart lesions were the most prevalent type found in this study, followed by Hill-Sachs lesions. Rotator cuff lesions had the lowest prevalence. Hill-Sachs lesions were more prevalent among patients with shorter duration of symptoms. It was not possible to affirm that, in patients with chronic instability of the shoulder, the numbers of associated lesions increased with the duration of symptoms or with the number of episodes of dislocation. 


\section{REFERENCES}

1. Kazár B, Relovszky E. Prognosis of primary dislocation of the shoulder. Acta Orthop Scand. 1969;40(2):216-24.

2. Hovelius L. Incidence of shoulder dislocation in Sweden. Clin Orthop Relat Res. 1982;(166):127-31.

3. Goss TP. Anterior glenohumeral instability. Orthopedics. 1988;11(1):87-95.

4. Henry JH, Genung JA. Natural history of glenohumeral dislocation--revisited. Am J Sports Med. 1982;10(3):135-7.

5. Hovelius L. Anterior dislocation of the shoulder in teen-agers and young adults Five-year prognosis. J Bone Joint Surg Am. 1987;69(3):393-9.

6. Hovelius L. Shoulder dislocation in Swedish ice hockey players. Am J Sports Med. 1978;6(6):373-7.

7. Hovelius L, Augustini BG, Fredin H, Johansson O, Norlin R, Thorling J. Primary anterior dislocation of the shoulder in young patients. A ten-year prospective study. J Bone Joint Surg Am. 1996;78(11):1677-84.

8. Yiannakopoulos CK, Mataragas E, Antonogiannakis E. A comparison of the spectrum of intra-articular lesions in acute and chronic anterior shoulder instability. Arthroscopy. 2007;23(9):985-90.

9. Hovelius L, Eriksson K, Fredin H, Hagberg G, Hussenius A, Lind B, et al. Recurrences after initial dislocation of the shoulder. Results of a prospective study of treatment. J Bone Joint Surg Am. 1983;65(3):343-9.

10. Norlin R. Use of Mitek anchoring for Bankart repair: a comparative, randomized, prospective study with traditional bone sutures. J Shoulder Elbow Surg 1994;3:381-5

11. Palmer I, Widen $A$. The bone block method for recurrent dislocation of the shoulder joint. J Bone Joint Surg Br. 1948;30(1):53-8.

12. Rowe CR, Patel $D$, Southmayd WW. The Bankart procedure: a long-term endresult study. J Bone Joint Surg Am. 1978 ;60(1):1-16
13. Symeonides PP. The significance of the subscapularis muscle in the pathogenesis of recurrent anterior dislocation of the shoulder. J Bone Joint Surg Br. 1972;54(3):476-83

14. Calandra JJ, Baker CL, Uribe J. The incidence of Hill-Sachs lesions in initial anterior shoulder dislocations. Arthroscopy. 1989;5(4):254-7.

15. Resnick D, Goergen TG, Niwayama G. Physical injury. In: Manke D, ed. Diagnosis of bone and joint disorders. 2nd ed. Philadelphia: Saunders; 1988. p. 2757-994.

16. Danzig LA, Greenway G, Resnick D. The Hill-Sachs lesion. An experimental study. Am J Sports Med. 1980;8(5):328-32.

17. Bankart AS. Recurrent or habitual dislocation of the shoulder-joint. Br Med J. 1923;2(3285):1132-3.

18. Bankart AS. The pathology and treatment of recurrent dislocation of the shoulder-joint. Br J Surg. 1938;26(1):23-9.

19. Thomas SC, Matsen FA 3rd. An approach to the repair of avulsion of the glenohumeral ligaments in the management of traumatic anterior glenohumeral instability. J Bone Joint Surg Am. 1989;71(4):506-13.

20. Andrews JR, Carson WG Jr, McLeod WD. Glenoid labrum tears related to the long head of the biceps. Am J Sports Med. 1985;13(5):337-41.

21. Snyder SJ, Karzel RP, Del Pizzo W, Ferkel RD, Friedman MJ. SLAP lesions of the shoulder. Arthroscopy. 1990;6(4):274-9.

22. Maffet MW, Gartsman GM, Moseley B. Superior labrum-biceps tendon complex lesions of the shoulder. Am J Sports Med. 1995;23(1):93-8.

23. Loew M, Thomsen M, Rickert M, Simank HG. [Injury pattern in shoulder dislocation in the elderly patient]. Unfallchirurg. 2001;104(2):115-8.

24. Hawkins RJ, Bell RH, Hawkins RH, Koppert GJ. Anterior dislocation of the shoulder in the older patient. Clin Orthop Relat Res. 1986;(206):192-5. 